\title{
DESAFIOS CÉTICOS E O DEBATE INTERNALISMO VERSUS EXTERNALISMO EM EPISTEMOLOGIA
}

Alexandre Meyer Luz*

RESUMO - Neste ensaio, pretendemos (1) sugerir algumas vantagens da apresentação do ceticismo na forma de um argumento cético geral, (2) discutir o princípio de fechamento utilizado neste argumento, (3) mostrar que o confiablismo externalista é incapaz de explicar as implicações deste argumento geral e (4) defender uma posição internalista cancelabilista como a mais adequadamente munida de ferramentas para avaliação dos desafios céticos.

PALAVRAS-CHAVE - Ceticismo. Internalismo. Externalismo.
ABSTRACT - In this essay, I intend to (1) show some advantages of presenting skepticism by means of a general skeptical argument, (2) discuss the closure principle implicit in such an argument, (3) suggest that externalist reliabilism is unable to account for what is implied by this general argument, and (4) maintain that an internalist defeasibility theory is the one best suited for assessing skeptical challenges.

KEYWORDS - Skepticism. Internalism. Externalism.

\section{Introdução}

O termo "ceticismo" é utilizado tendo como referências diferentes exercícios intelectuais. Michael Williams, em sua obra Problems of Knowledge ${ }^{1}$ sugere uma distinção entre "ceticismo teórico" e "ceticismo prático". Manterei esta terminologia aqui, mas com um significado distinto do de Williams: por ceticismo teórico, eu me referirei (assim como Williams) àquele conjunto de desafios céticos direcionados às nossas pretensões de posse de conhecimento; por ceticismo prático ${ }^{2}$

* Professor do Departamento de Filosofia da Universidade Federal de Santa Catarina e membro do GT Epistemologia Analítica da ANPOF. Agradeço aos apoios do CNPq e do PAIRD-UFS, que financiaram esta pesquisa.

1 Cf. Michael Williams, Problems of Knowledge, p. 58ss.

2 Williams sugere a expressão "ceticismo prático" para atitudes práticas de desconfiança em relação a crenças como "Deus existe", por exemplo.

\begin{tabular}{|l|l|l|l|l|l|}
\hline VERITAS & Porto Alegre & v. 54 & n. 2 & maio/ago. 2009 & p. 74-95 \\
\hline
\end{tabular}


eu me referirei (diferentemente de Williams) ao conjunto de eventuais conclusões não-epistemológicas que alguém possa derivar das conclusões de desafios céticos até o campo da ética ou qualquer outro território. No que segue, pois, eu me ocuparei apenas do ceticismo teórico, e mais particularmente da discussão sobre alguns argumentos céticos e suas consequências, tais como as teses de que

(TC) i) não podemos saber que sabemos $P$, ou

ii) não podemos estar justificados em saber que $P$, ou

iii) não podemos saber que $P$, ou

iv) não podemos crer justificadamente que $P$.

ou outras variações possíveis de teses contra a posse de conhecimento ou de justificação. ${ }^{3}$ Em um primeiro momento, estarei interessado em oferecer uma apresentação do que me parece ser um argumento cético geral, subjacente às várias formas de ceticismo teórico, defendendo que um argumento cético é um desafio primeiramente epistemológico (e apenas acidentalmente um problema metafísico ou derivado de uma concepção errônea sobre a mente ou a linguagem), e um desafio que se estabelece não necessariamente a todo um conjunto de crenças de um determinado tipo. Com isso, procurarei mostrar que formas mais sofisticadas de desafios céticos estão ligadas a uma experiência epistemicamente corriqueira, a experiência de formação de crenças, que não pode ser justificadas até a última instância possível, mas também mostrarei que isso não inviabiliza qualquer forma de justificação. Adicionalmente, procurarei mostrar que a estratégia de estabelecer os desafios céticos como argumentos primariamente epistemológicos fornece uma ferramenta heuristicamente importante, forçando o esclarecimento de postulados epistemologicamente centrais. Depois, em um segundo momento, pretendo utilizar esta ferramenta no debate entre teorias internalistas e externalistas da justificação.

\section{Desafios céticos}

Segundo o cético, pelo menos um dos disjuntos de (TC) será aplicado a enunciados que comumente aceitamos como passíveis de conhecimento ou justificação, tais como:

3 Cada uma destas teses tem, certamente, um grau de força diferente e implicações diferentes. Se afirmo que $S$ não pode estar justificado em crer que $P$, então eu assumo uma tese arrasadora contra a possibilidade de crença racional (em uma leitura internalista) ou contra a possibilidade de que nosso equipamento cognitivo se relaciona adequadamente com o mundo exterior, mesmo dada a possibilidade eventual de erro (em uma leitura externalista). Se assumo que $S$ não pode saber que sabe $P$, então eu posso aceitar a posse de crença justificada e até de crença verdadeira justificada. A segunda tese é, certamente, bem mais fraca do que a primeira. 
(1) Eu tenho uma mão

Eu não sou um cérebro em uma cuba

Todos os cisnes são brancos

Aquilo é uma zebra

Um desafio cético a enunciados como (1)-(4) valer-se-á de uma estratégia como o seguinte esquema geral do argumento cético:

(ACG) 1. Se um sujeito $S$ sabe que $P$, então ele sabe que não é o caso que $R(\mathrm{Skp} \rightarrow \mathrm{Sk} \sim \mathrm{r})$;

2. $S$ crê que ninguém pode saber que não é o caso que $R(\sim \mathrm{Sk} \sim \mathrm{r})$;

3. Logo, ninguém sabe que $P$ ( $\sim \mathrm{Skp})$,

onde $P$ é um enunciado empírico qualquer, como (1)-(4) acima. (ACG) é um argumento claramente válido (um modus tollens) e vamos supor aqui que o que está em disputa não é a validade do argumento. ${ }^{4} \mathrm{O}$ recurso ao modus tollens pode ser explicado quando consideramos que um ataque direto a $P$ (a simples afirmação de que $P$ é falsa, ou a de que não podemos saber que $P$, etc.) soaria brutalmente contraintuitivo, já que a suposição corrente (e útil) é a de que o conhecimento de $P$ é uma experiência comum. Afirmar simplesmente que $P$ não é conhecida reduziria a tese cética a uma posição de desconfortável dogmatismo. $O$ modus tollens acima, em contrapartida, oferece um argumento bastante simples e inicialmente muito plausível em favor da tese cética, já que também é uma experiência corrente a de que há muitas proposições $R$ que simplesmente não podemos saber, sob condições correntes, tais como "há outras formas de vida inteligente no universo e elas são bípedes", "há exatamente $x$ leões selvagens na África, neste instante", etc. Além disso, (ACG) também pode satisfazer aos filósofos, já que as razões que levam $S$ a duvidar da possibilidade de saber que $R$ podem ser estabelecidas por conta de hipóteses céticas tradicionais, tais como cérebros em cubas, gênios malignos, falhas em induções, etc.

Quais enunciados podem ocupar o lugar de $R$ no (ACG)? É claro que $R$ deve, de algum modo, ser incompatível com $P$. Uma primeira hipótese, portanto, seria a de supor que $R$ deve ser uma contraditória de $P$. Parece plausível imaginar, de saída, que, se eu sei que $P$, então devo ser capaz de saber que não é o caso de que $\sim P$. Se eu sei que tenho uma mão, parece evidente imaginar que eu sei que é falso que eu não tenho uma mão.

Todavia, o conjunto das proposições que podem ocupar o lugar de $R$ não se restringe ao conjunto das contraditórias de $P$. Tome por exemplo:

4 Como afirmamos anteriormente, o ceticismo parece ser uma tese interessante enquanto desafia espantosamente as nossas pretensões comuns de conhecimento e enquanto, por conta disto, nos faz pensar sobre conceitos filosoficamente importantes. A segunda tarefa não seria realizada por um tipo de ceticismo que colocasse sob questão a validade de qualquer forma de argumento. 
$S$ vai ao zoológico e, diante de uma jaula que ostenta uma placa onde se lê "zebras", ele vê animais que aparentam ser exatamente como zebras e, por isso, ele crê que $Z$, que os animais são zebras, e imagina que sabe que são zebras. Todavia, alguém lhe diz que $M$, que os animais são, na verdade, mulas pintadas, parte de um plano da diretoria para aumentar o número de visitantes. Já que ele não consegue descartar tal hipótese naquele momento, então ele não sabe, naquele momento, que os animais são zebras. ${ }^{5}$

Note que, neste caso, a hipótese $M$ não é uma proposição contraditória de $Z$; todavia, parece inicialmente razoável imaginar que $Z$ não pode ser conhecida sem que $M$ seja descartada por $S$, já que $M$ e $Z$ concorrem, enquanto parece claro que as duas não podem ser simultaneamente verdadeiras, neste caso.

Uma hpótese competidora, $R$, não precisa sequer concorrer diretamente com a proposição em questão. Imagine que eu suponha que sei que $C$ "eu tenho um corpo". Neste caso, considere a hipótese $X$ "suas percepções são induzidas por um supercomputador ligado ao seu cérebro". $X$ não é uma competidora direta de $C$, já que eu posso ter percepções induzidas por um computador e ter um corpo. Todavia, se considerarmos que a justificação (e daí, que o conhecimento) de $C$ depende de informações advindas dos sentidos e que $X$ coloca em questão a confiabilidade de nossos sentidos, então parece ser o caso de que $X$ deve ser descartada por uma pessoa $S$, se $S$ pretende saber que $C$. Temos, então, uma explicação para $R$ como sendo uma hipótese competidora de $P$ :

(HC) Uma proposição $R$ é uma hipótese competidora para $P$ no instante $t$ para o sujeito $S$ se:

(i) (a) $R$ é uma contraditória de $P$; ou

(b) $R$ é uma contrária de $P$; ou

(c) $R$ implica logicamente uma proposição que é uma contraditória ou contrária de $P$; ou

(d) $R$ fornece justificação prima facie para uma proposição $R^{\prime}$ que é uma contraditória ou contrária de $P$; ou

(e) $R$ é ou sustenta um eliminador $E$ daquilo que fornece justificação para $P$; e

(ii) $S$ acredita em $R$ e percebe as relações entre $R$ e a crença que diretamente compete com $P$ (em (c), (d) ou em (e)). ${ }^{6}$

5 Este exemplo foi inspirado no exemplo de Fred Dretske, Epistemic Operators, in: Journal of Philosophy, p. 1007-1023.

6 A cláusula (ii) talvez possa ser objeto de disputa. Poder-se-ia optar pela segunda variação: se $S$ acreditasse em um dos disjuntos de (i), então $S$ teria uma hipótese competidora para $P$, e supor que $S$ não pode saber que $P$ se ele tem ou se há potencialmente uma hipótese competidora não eliminável para $P$ (uma hipótese que, se $S$ nela cresse, então ela competiria com $P$ ). Isto não muda significativamente o ponto, já que parece ser pouco razoável aceitar que a mera possibilidade da existência de uma hipótese competidora constitua, ela mesma, uma hipótese competidora. 
Os disjuntos em (i) dão conta de uma grande variedade de desafios céticos (como veremos adiante). Vejamos, agora, a segunda premissa de (ACG). Ela é considerada, normalmente, o lugar onde o cético se instala, procurando mostrar que afirmar a falsidade de $R$ é algo que não acidentalmente está além das possibilidades de $S .{ }^{7} S$ não é capaz de realizar tal tarefa por pelo menos uma das seguintes razões: $R$ está além da sua capacidade de observação (já que postula a possibilidade de existência de entidades além dos poderes de observação de $S$, em $t$, tais como demônios zombeteiros ${ }^{8}$ ou supercomputadores ligados ao nosso córtex cerebral) ou $R$ é uma crença não-eliminável, em $t$, sobre a inadequação da estrutura das razões de $S$ para $P$. Esta última hipótese remete a problemas bem conhecidos, como por exemplo, o que decorre do seguinte:

(MA) $S$ postula conhecimento de que $P$, e imagina, por definição, que está justificado em crer que $P$. $R$ é uma proposição que sustenta $R^{\prime}$, que afirma, por sua vez, que " $S$ não está justificado em crer que $P$ ". $R$ diz que toda justificação para uma proposição depende ou de fundamentos arbitrários, ou de raciocínio circular, ou de uma cadeia infinita de razões, e que nenhum destes três modos é capaz de conferir justificação (logo, $\left(R^{\prime}\right)$ é o caso). Já que $S$ não consegue eliminar $R$ (e, daí, $\left.\left(R^{\prime}\right)\right)$, então $S$ não sabe que $P^{9}$

Neste caso, a proposição competidora $R$ é do tipo (e) de (HC) e $R$ é ela mesma não-eliminável (suponhamos), porque, para eliminar $R$ (e daí $\left.R^{\prime}\right)$, preciso usar $R$, caindo em petição de princípio.

Algo semelhante ocorre no seguinte tipo de desafio humeano:

1. Todas as nossas crenças sobre o mundo exterior dependem para sua evidência das aparências sensíveis, junto com a suposição de que (A2) aparências sensíveis são guias confiáveis para a realidade exterior;

2. Mas, (A2) é ela mesma uma crença sobre o mundo exterior;

3. Portanto, a suposição (A2) depende para a sua evidência de (A2); $(1,2)$

4. Raciocínio circular não pode dar origem a conhecimento;

5. Portanto, (A2) não é conhecida; $(3,4)$

7 Note que, como vimos, uma das premissas de (ACG) é ( $\mathrm{Skp} \rightarrow \mathrm{Sk} \sim \mathrm{r}$ ). Se afirmo que sei que $P(\mathrm{Sp})$, então, por uma dedução válida, obtém-se que eu sei que $R(\mathrm{Sk} \sim \mathrm{r})$, que eu sei, por exemplo, que não sou um cérebro em uma cuba e etc. O conhecimento é, deste modo, fácil. O problema do conhecimento fácil foi desenvolvido por Stewart Cohen, Basic Knowledge and the Problem of Easy Knowledge, in: Philosophy and Phenomenological Research, p. 309-329).

8 Para lembrar a famosa hipótese cartesiana da primeira meditação.

9 Este exemplo foi obviamente inspirado nos modos de Agripa. Não estou aqui sugerindo um uso acadêmico para os tropoi. Estou apenas sugerindo que eles podem ser utilizados de um modo acadêmico, como uma ferramenta para o ceticismo teórico. 
6. Todas as nossas crenças sobre o mundo dependem de uma suposição que não é conhecida; $(1,5)$

7. Crenças que dependem de suposições não conhecidas não são elas mesmas conhecidas;

8. Portanto, ninguém sabe coisa alguma sobre a realidade exterior. $(6,7)^{10}$

Desafios mais gerais, como (MA) e (H2), são filosoficamente mais interessantes. Primeiramente, porque são racionalmente mais desafiadores, enquanto se utilizam de suposições que parecem altamente plausíveis (como $R$ em (MA) e a premissa 4 de (H2)). Em segundo lugar, porque eles prestam um melhor serviço em revelar as formas pelas quais os nossos julgamentos sobre áreas do nosso suposto conhecimento podem ser desafiados. Isso mostra a importância teórica do desafio cético para a epistemologia: ele guia os epistemólogos na direção de um aprofundamento da compreensão de conceitos como os de conhecimento e de crença justificada. Todavia, uma forma simples de argumento como (ACG) nos permite perceber que o ceticismo é um problema teórico poderoso para qualquer indivíduo, e não apenas uma tecnicidade filosófica. Isso fica claro quando consideramos que "eliminar hipóteses contrárias" parece ser um conselho útil para qualquer decisão cotidiana, e que mesmo alguém sem qualquer contato com a tradição da especulação filosófica pode chegar, por mera generalização, dada a experiência corrente de, no instante $t$, não ser capaz de eliminar hipóteses contrárias, a um argumento como (ACG), e aplicá-lo a um campo considerável de proposições empíricas.

Essa última possibilidade nos leva a algo que deve ser notado: (ACG) não está comprometido, inicialmente, com a extensão do ataque cético. De acordo com a proposição que ocupa o lugar de $R$ no argumento, um território de proposições pode ser colocado em questão. (ACG) não está comprometido necessariamente com um ceticismo global ou sequer com um desafio de todo um conjunto de crenças de um dado território, de uma só vez; cada uma das crenças pode ser desafiada, uma após a outra.

Os desafios céticos ficam constituídos, por fim, como um tipo de desafio que pode se instalar a partir de pressupostos muito simples, abundantes em nossas experiências correntes como agentes epistêmicos. Isso é particularmente importante para o nosso objetivo de utilizar os desafios céticos como ferramentas heurísticas para a investigação epistemológica, ferramentas capazes de aprofundar nossa compreensão

10 Esta é uma das versões sugeridas por John Greco para o argumento humeano; cf. John Greco, Putting Skeptics in Their Place - The Nature of Skeptical Arguments and their Role in Philosophical Inquiry, p. 29. 
de princípios epistêmicos subjacentes aos nossos julgamentos cotidianos de crenças e às nossas teorias epistemológicas.

Por fim, (ACG) tem a vantagem de permitir que visualizemos rapidamente um outro problema, o problema do conhecimento fácil, como desenvolvido por Stewart Cohen: ${ }^{11}$ suponha que eu tenha crença justificada (e que não estou em uma situação de tipo Gettier) de que há um objeto vermelho sobre a mesa, e há efetivamente um objeto vermelho sobre a mesa; pelo fechamento, sei daí que tal objeto não é branco iluminado por lâmpadas vermelhas. Formalmente, temos agora o seguinte modus ponens:

(PCF) 1. Se um sujeito $S$ sabe que $P$, então ele sabe que não é o caso que $R(\mathrm{Skp} \rightarrow \mathrm{Sk} \sim \mathrm{r})$;

2. $S$ sabe que $P$ (Skp);

3. Logo, $S$ sabe que $R$ não é o caso $(S k \sim r)$.

Já que não tenho qualquer evidência direta em favor da crença de que ele não é branco e iluminado por luzes vermelhas, parece que o conhecimento de que ele não é branco e iluminado por luzes vermelhas foi obtido de modo excessivamente fácil. $E$, já que a tese de partida de qualquer tipo de teoria epistemológica deve ser a de que mesmo que alguém assuma a idéia de que os casos de conhecimento não são raros (o que parece ser um otimista suposição do senso comum), ele não deveria assumir que alguém poderia obter legitimamente conhecimento de um modo assim tão fácil (já que as nossas intuições comuns remetem à idéia de que o conhecimento, de algum modo, deve satisfazer à tese de que a verdade deve ser obtida de modo não acidental), parece que temos, aqui, uma conclusão contraintuitiva.

\section{Ceticismo e epistemologia}

Como mencionamos, os desafios céticos se impuseram desde os primórdios da investigação filosófica e, durante toda a tradição, inúmeros filósofos tentaram escapar de tais desafios. ${ }^{12}$ Tais respostas frequentemente apelaram para estratégias como a apresentação de metafísicas alternativas (apresentando, por exemplo, uma metafísica que "não caísse na dicotomia entre sujeito e objeto"), que supostamente não abririam espaço para os desafios céticos. Versões contemporâneas de estratégias desta natureza têm apelado para considerações sobre a

11 Cf. Stewart Cohen, Structure and Connection: Comments on Sosa's Epistemology, in: John Greco (ed.), Sosa and his Critics, 2004, p. 17-21.

12 Para uma perspectiva histórica do problema, cf., por exemplo, Richard Popkin, The History of Scepticism from Savonarola to Bayle, 2003. 
natureza da mente, da linguagem ou da crença. Richard Foley, todavia, apresenta duas boas razões contra este projeto. Diz ele:

Há duas razões primárias que atingem qualquer tentativa de utilização de uma metafísica da crença, verdade ou referência para dissolver preocupações céticas. Primeiro, mesmo nas leituras mais fortes destas abordagens metafísicas, ainda há muito espaço para o erro, e se não houvesse esta seria uma boa razão para rejeitar esses tratamentos. Segundo, dúvidas céticas podem ser estabelecidas contra os argumentos utilizados para defender essas abordagens metafísicas, e a própria metafísica não pode erradicar inteiramente tais dúvidas. ${ }^{13}$

A observação acima se coaduna com a observação que encerrou a seção anterior. Já que o objeto do (ACG) pode ser uma proposição $P$ qualquer e não necessariamente um conjunto de proposições, a segunda premissa de (ACG) dificilmente será mostrada falsa, para todas as instâncias do argumento. (ACG) não depende necessariamente das hipóteses céticas tradicionais (incluindo gênios malignos e cérebros numa cuba), mas, antes, está firmemente calcada nas nossas experiências corriqueiras de erro e de limitação de nossos poderes epistêmicos.

Todavia, talvez não só as tentativas metafísicas de solução do ceticismo falhem, mas também as tentativas epistemológicas. Foley, por exemplo, sustenta que:

Preocupações céticas são inescapáveis, e a reação apropriada a esse fato sobre as nossas vidas intelectuais é a aceitação, não o contrário. A nossa falta de garantias não circulares sobre nossa confiabilidade não é uma falha que precisa ser corrigida, mas antes uma realidade que precisa ser reconhecida. Precisamos reconhecer a nossa vulnerabilidade ao erro e reconhecer também que investigar sempre envolve um elemento substancial de confiança em nossas próprias faculdades intelectuais e na opinião que elas geram, algo necessário que não pode ser eliminado por investigações adicionais. ${ }^{14}$

Não nos parece, porém, que a concessão feita por Foley possa ser feita sem qualificações adicionais. Um argumento como (ACG) pode não só se constituir em uma estratégia para a negação da posse de conhecimento, mas também atingir a noção de racionalidade. Sendo assim, mesmo que tenhamos que conceder em dada instância o sucesso ou mesmo a inescapabilidade dos ataques céticos, podemos pelo menos defender a possibilidade de conhecimento e de crença racional em outras instâncias. Essa observação guiará boa parte da discussão posterior: mesmo que não sejamos capazes de oferecer um contra-argumento para todos os argumentos céticos, podemos limitar o alcance dos desafios

13 Cf. Richard Foley, Three Attempts to Refute Skepticism and Why they Fail, in: Steven Luper (ed.), The Skeptics - Contemporary Essays, p. 64-65.

14 Id. ibid., p. 72. 
céticos de modo a permitir que eles se acomodem às nossas intuições pré-teóricas epistemicamente otimistas e, ao mesmo tempo, mantendo aquele tipo de plausibilidade inicial que lhes concedemos anteriormente. Adicionalmente, poderemos testar as teorias epistemológicas que desenvolvemos para dar conta de tais intuições contra os argumentos, avaliando a sua capacidade explicativa.

\section{Princípio de fechamento, ceticismo e conhecimento fácil}

Concedemos que o argumento cético geral (ACG) era válido, já que ele é uma instância de um modus tollens. Todavia, não podemos perder de vista o que está em jogo, para o argumento: a transmissão de conhecimento (não de verdade) das premissas para a conclusão. O ponto então é: um argumento qualquer, mesmo sendo válido, se fecha sobre o conhecimento, do mesmo modo que se fecha sobre a verdade? Tomemos, por exemplo, o seguinte princípio do fechamento para o conhecimento:

(PFC1) Se $S$ sabe que $X$ e se $X$ implica $Y$, então $S$ sabe que $Y$.

Esta apresentação de um princípio do fechamento para o conhecimento é inadequada, e isto pode ser facilmente demonstrado pelo seguinte caso: $S$ sabe que $X$; $Y$ é uma disjunção obtida a partir de $X ; S$ nunca estudou lógica e nunca se deu conta de que (A, portanto (A v B)) é válida; $S$ não crê em (A v B), ou crê em ( $\mathrm{A} \vee \mathrm{B}$ ) por outra razão que não sua dedução a partir de A. Portanto, mesmo que S saiba $\mathrm{A}$, já que a crença não se fecha necessariamente via dedução, $S$ não sabe que (A v B).

Esta dificuldade pode ser facilmente eliminada com esta nova versão para o princípio:

(PFC2) Se $S$ sabe que $X$, se $X$ implica $Y$, e se $S$ percebe a implicação, então $S$ sabe que $Y$.

(PFC2), todavia, ainda não é um princípio adequado, já que mesmo quando $S$ percebe a implicação entre $X$ e $Y, S$ pode não crer em $Y ; S$ pode simplesmente não formar, por alguma razão qualquer, além do seu controle, a crença de que $Y$. Por conta disto, parece ser mais prudente abandonar a busca por um princípio do fechamento para o conhecimento em favor da busca por um princípio do fechamento para a justificação. Como primeiro candidato a tal princípio podemos sugerir o seguinte:

(PFJ1) Se $S$ está justificado em crer que $X$, se $X$ implica $Y$ e se $S$ percebe a implicação, então $S$ está justificado em crer que $Y$.

$\mathrm{E}$, para eliminar completamente qualquer menção à crença:

(PFJ2) Se $X$ está justificada para $S$, se $X$ implica $Y$ e se $S$ percebe a implicação, então $Y$ está justificada para $S$. 
Um princípio do fechamento como (PFJ2) parece ser intuitivamente bastante plausível, e tem sido consenso na literatura recente aceitá-lo, pelo menos como caminho possível para a transmissão da justificação. ${ }^{15}$ Todavia, se o princípio de fato é correto, então parece que é inevitável aceitar a conclusão cética, alegará o cético, como mostrou Dretske. ${ }^{16}$ Isto tudo parece mostrar que a primeira premissa de (ACG) esconde mais problemas do que normalmente supomos e que, por isso, deveríamos melhor compreender o seu papel nos argumentos céticos.

\section{Externalismo, ceticismo e o princípio do fechamento}

O externalismo epistemológico constitui-se de uma ampla família de teorias do conhecimento ou da justificação epistêmica que têm em comum a dispensa do requisito de acessibilidade para a justificação epistêmica. Enquanto a tradição, tipicamente internalista, exige que aquilo que justifica para um sujeito $S$ uma crença $P$ em questão seja algo interno e "transparente" ou acessível para $S$, o externalista requer apenas que alguma condição de conexão não-acidental com a verdade seja satisfeita. Assim, condicionalmente, se um processo cognitivo $X$ tende a produzir mais verdades do que falsidades, então a mera ocorrência da crença em $P$, causada por $X$, faz com que P esteja justificada para $S,{ }^{17}$ sem que seja necessário que $S$ tenha qualquer informação - ou sequer que ele seja capaz de ter qualquer informação - sobre a confiabilidade de $P$. Em outros termos, o externalismo - contrariamente ao internalismo, permite uma "cláusula da não-acessibilidade" (CNA) embutida na explicação da justificação epistêmica.

A abordagem externalista confiabilista parece inicialmente trazer algumas vantagens evidentes, quando pensamos em alguns desafios céticos tradicionais. Tomemos, por exemplo, (H2). Ali, a tese (A2) deve ser tomada como um julgamento sobre a confiabilidade dos processos formadores de crenças que têm como entrada aparências sensíveis. Mas, se (CNA) é aceita, então a Premissa 1 de (H2) é falsa (já que nem todas as nossas crenças dependem da suposição A2) e, consequentemente,

15 Edmund Gettier valeu-se de um princípio do fechamento para a justificação para estabelecer seus famosos contraexemplos (cf. Edmund Gettier, Is Justified True Belief Knowledge?, in: Analysis, p. 121-123). Formas de apresentação do princípio vêm sendo criticadas (cf., por exemplo, Cláudio de Almeida, Closure, Defeasibility and Conclusive Reasons, in: Acta Analitica, p. 301-319), mas não há consenso se existem de fato contra-exemplos ao princípio e, se existem, qual a extensão dos danos causados.

16 Cf. Fred Dretske, Epistemic Operators, op. cit., p. 1007-1023.

17 Esta é uma apresentação de uma versão tipicamente confiabilista de externalismo. Esta não é a única versão, mas é certamente a mais popular. 
(H2) é incorreto. Se qualquer interpretação do argumento humeano envolver (A2), então temos uma estratégia para contornar o desafio humeano.

Para um externalista, as atribuições de conhecimento - mas, não necessariamente as autoatribuições de conhecimento, já que elas podem exigir um tipo de crença sobre a confiabilidade dos processos formadores da crença em questão que $S$ muito provavelmente não será capaz de justificar adequadamente, seja por não dispor deste tipo de informação, seja por conta dos próprios desafios céticos - são muito provavelmente abundantemente corretas, em um sentido que nos interessa aqui: o sujeito epistêmico do qual é dito saber que $P$ não precisa dispor de evidências para $P$ (supondo que $P$ foi formada por um processo confiável de formação de crenças) e, deste modo, não será vítima dos desafios céticos.

Isto parece oferecer uma estratégia que convenientemente parece simplesmente dissolver (ACG): não precisamos estabelecer relações inferenciais para a justificação de $P$ e não precisamos, do mesmo modo, avaliar as hipóteses competidoras que concorrem com $P$. A primeira premissa de (ACG) é falsa, portanto os desafios céticos não se instalam.

Infelizmente, todavia, o parágrafo anterior contém pelo menos um erro, além de algumas considerações excessivamente gerais. É excessivamente grosseiro descartar a necessidade de eliminação de hipóteses competidoras em todos os casos. Mesmo que a (CNA) esteja correta, ela não é uma cláusula que impeça crenças que $S$ conscientemente sustenta inferencialmente em outras proposições; e ela, certamente, do mesmo modo não impede que $S$ creia em uma proposição que é uma hipótese competidora de $P$ e nem que $S$ perceba a (ou seja avisado da) relação inferencial entre esta crença e $P$. Assim, a primeira premissa de (ACG) não é de modo algum falsificada pela aceitação de (CNA). ${ }^{18} \mathrm{E}$, deste modo, ela não resolve os desafios céticos, do modo e com o alcance que eles foram apresentados anteriormente. O confiabilismo pode ser um antídoto para uma tese grosseira como a de que "o conhecimento de proposições empíricas não é possível, em nenhum caso", mas os desafios céticos sequer precisam se comprometer com tal tipo de tese geral. Um eventual usuário do (ACG) poderia simplesmente dizer: "eu não estou interessado em discutir se temos ou não conhecimento, no geral. Eu estou interessado apenas, neste momento, em discutir se você pode saber que $P$, dadas tais e tais hipóteses contrárias".

18 Greco aceita explicitamente o princípio de fechamento. Cf., por exemplo, o seu External World Skepticism, in: Philosophical Compass, seção 1, p. 626 e ss. 
Mesmo que aceitemos a cláusula de não-acessibilidade (CNA) e, com isso, nos livremos da necessidade de relações inferenciais para a justificação prima facie, a eliminação das hipóteses competidoras ainda parece ser necessária. $\mathrm{E}$ parece que o confiabilismo genérico sugerido acima é incapaz de oferecer um tratamento para este problema.

Uma sugestão de abordagem para este problema é sugerida por John Greco, especialmente na obra Putting Skeptics in their Place, ${ }^{19}$ e ela é exemplar de um tipo de estratégia comum entre os confiabilistas. A estratégia utilizada por Greco pode ser resumida em dois grandes passos: (1) acrescentar ao confiabilismo genérico uma cláusula que permita explicar como o sujeito epistêmico pode ter sensibilidade em relação às próprias crenças; ${ }^{20}$ (2) oferecer um tratamento para mostrar que as hipóteses competidoras que eventualmente se instalarem não são de fato alternativas relevantes à proposição em questão.

O primeiro passo, no caso de Greco, é realizado por um apelo à idéia de que o conhecimento deve ser fruto de um caráter virtuoso do agente. Ele diz: "a idéia central é a de definir conhecimento em termos de caráter cognitivo virtuoso, e definir caráter virtuoso em termos de motivação apropriada e confiável para o sucesso". ${ }^{21}$ A posse de um caráter virtuoso, supõe Greco, permite que $S$ tenha o tipo de sensibilidade sobre a confiabilidade de seus próprios processos formadores de crenças que é capaz de eliminar os problemas que a questão da percepção subjetiva da justificação causa ao confiabilismo genérico e, no nosso caso, indispensáveis para a autoatribuição de conhecimento. ${ }^{22}$ Asua proposta é a seguinte:

(VJ) Uma crença está subjetivamente justificada para uma pessoa $S$ se e somente se a crença de $S$ em $p$ está fundada nas disposições cognitivas que $S$ manifesta quando $S$ está pensando conscientemente. ${ }^{23}$

Note que $S$ não precisa estar "pensando conscientemente" no instante $t$ para que a sua crença $P$ esteja justificada em $t$. A reflexão tem, para Greco, um papel central na formação do caráter epistemicamente virtuoso

19 Cf. John Greco, Putting Skeptics in Their Place - The Nature of Skeptical Arguments and their Role in Philosophical Inquiry, 2000.

20 Seguindo, aqui, a estratégia inaugurada por Ernest Sosa, The Raft and the Pyramid: Coherence versus Foundations in the Theory of Knowledge, in: Midwest Studies In Philosophy, 1980, p. 3-26, onde é sugerida a incorporação da noção de virtude intelectual ao projeto confiabilista.

21 Cf. John Greco, Putting Skeptics in Their Place, p. 5.

$22 \mathrm{O}$ (ACG) é particularmente adaptado para situações em que S é obrigado a avaliar a justificação para suas crenças, como nas situações de autoatribuição responsável de conhecimento.

${ }^{23}$ Cf. John Greco, op. cit., 2000. 
de $S$, a longo prazo, valorizando aqueles procedimentos intelectuais que parecem ser condutores-à-verdade. Todavia, em $t$, não é necessário que $S$ manifeste um compromisso explícito com a busca da verdade (e, assim, $S$ não precisa de evidências, em t, em favor de $P$ ), mas apenas que $P$ não tenha sido formada de modo espúrio. Se $S$ tem um caráter epistemicamente virtuoso, então ele está protegido da ação de processos espúrios de formação de crenças e tenderá a escapar imune da demanda por revisão do seu sistema de crenças. Isto permite o enfrentamento de uma primeira categoria de desafios ao conhecimento de $P$ por $S$ : se $S$ crê de modo prima faciejustificado em $P$, é de se supor que $S$ possa não dispor de justificação ultima facie em favor de $P$. Por exemplo, a crença em $\mathrm{P}$ pode ser desafiada por uma hipótese competidora, como já vimos. Esta hipótese competidora pode ser uma crença antiga de $S$. Ela pode ser uma crença igualmente justificada, por exemplo. Neste caso, qualquer teoria da justificação deveria afirmar que, se $R$ e $P$ competem, então ou $S$ suspende o juízo ou apenas uma delas deve permanecer no sistema de crenças justificadas de $S$. Se $S$ é capaz de descartar ou $R$ ou $P$, então a crença concorrente é aquela que, no fim das contas, deve permanecer no sistema de crenças justificadas de $S$. Se $P$ está mais justificada do que $R$, então $P$ é que deve permanecer no sistema. Isto não pode ser explicado apenas com as ferramentas do confiabilismo genérico. Desse modo, a adição da noção de virtude visa ampliar os recursos conceituais do confiabilista, a fim de permitir uma primeira explicação para toda esta gama de fenômenos da vida intelectual do agente epistêmico, como as atribuições de responsabilidade intelectual, de racionalidade e de justificação epistêmica. Um indivíduo virtuoso $S$ pode formar crenças racionais sem ter que eliminar hipóteses competidoras em $t$, já que nem sempre há hipóteses competidoras dadas para $S$, em $t$. Ele pode eventualmente saber que $P$ de modo racional, o que reforça a carga que já o confiabilista genérico disparava contra as pretensões céticas.

A despeito disto, este primeiro passo da estratégia nada fala sobre (ACG). É necessário, pois, enfrentá-lo. A estratégia geral, no passo 2, consiste em tentar estabelecer um modo para restringir o grupo das alternativas que podem ser aceitas como concorrentes da proposição que é candidata ao conhecimento (como "estou sentado diante do fogo"), ou seja, o passo 2 consiste em um ataque à segunda premissa de (ACG), numa tentativa de enfraquecê-la. "Enfraquecê-la" porque não se trata de sustentar que a hipótese competidora é falsa; trata-se apenas de mostrar que, em muitos casos, ela não precisa ser considerada. Greco sugere uma abordagem que tem por base a semântica dos "mundos possíveis" da lógica modal. Segundo ele, 
a ideia é a de que é uma possibilidade lógica a de que eu sou um cérebro numa cuba ligado a um supercomputador programado para me iludir. Em outras palavras, há mundos possíveis nos quais este é o caso. Mas, tais mundos possíveis estão "distantes" do mundo real. Não há quaisquer mundos possíveis nos quais eu sou um cérebro numa cuba, sendo que "proximidade" deve ser entendido, de modo grosseiro, em termos de similitude global entre os mundos. A proposta é, então, a seguinte: uma possibilidade é relevante se ela é verdadeira em algum mundo possível próximo, e é irrelevante se não é. (...) Virtudes cognitivas são um tipo de poder ou habilidade. Em geral, habilidades são disposições estáveis e bem-sucedidas para atingir certos resultados sob certas condições. Mas, habilidades não podem ser definidas em termos apenas do mundo real. Pelo contrário, quando dizemos que alguém tem uma habilidade nós queremos dizer que ele provavelmente atingiria os resultados relevantes em uma variedade de condições similares àquelas que realmente se dão. (...) Mas, se o conhecimento envolve essencialmente ter habilidades cognitivas, e se habilidades são disposições para atingir resultados em mundos possíveis próximos, então isso explica porque possibilidades são relevantes apenas quando elas são verdadeiras em algum mundo possível próximo. Especificamente, apenas possibilidades como esta podem pôr sub judice as habilidades cognitivas de alguém. Em um ambiente onde ser enganado por demônios é real ou provável, eu não tenho a habilidade de confiavelmente formar crenças verdadeiras e evitar crenças falsas. Mas, se nenhum de tais demônios existe neste mundo ou em mundos similares, eles não afetam minhas faculdades e hábitos cognitivos. ${ }^{24}$

Ele não oferece, todavia, uma distinção cuidadosa entre um mundo possível "próximo" e um "distante". Mesmo que uma explicação dessas noções seja possível, porém, ainda é necessário equipar mais adequadamente a teoria. Qualquer teoria que pretenda oferecer uma explicação plausível para os desafios céticos precisa dar conta do fato de que se $S$ considera a plausibilidade de uma hipótese contrária à proposição em questão, então $S$ simplesmente parece não saber tal proposição, mesmo que a hipótese contrária seja verdadeira apenas num mundo possível distante. Uma hipótese contrária não depende de cenários céticos tradicionais. Como vimos, (ACG) pode ser estabelecido por generalização, a partir de experiências corriqueiras de erro. (ACG) não depende de cérebros numa cuba, gênios malignos ou o que o valha; ele não requer sequer que as hipóteses contrárias sejam verdadeiras ou sequer que elas estejam justificadas. Parece não ser um bom caminho apenas tentar desqualificar as hipóteses contrárias. Como o próprio Greco lembra, "o projeto é o de rejeitar algo no argumento cético, não importando se um cético "real" ficaria satisfeito com tal rejeição. Pondo de outro modo, o projeto é o de criticar o argumento cético e não o de convencer uma pessoa cética". ${ }^{25}$

${ }^{24}$ Id. ibid., p. 206-207.

${ }^{25}$ Cf. John Greco, External World Skepticism, op. cit., p. 628. Grifo nosso. 
O apelo à noção de mundos possíveis nada fala sobre um possível erro no (ACG).

Esta estratégia, mesmo que consiga superar as dificuldades associadas à explicação de noções metafísicas como a de "mundos possíveis próximos" (dificuldades que abrem as portas para dúvidas céticas sobre esta metafísica dos mundos possíveis, como advertia Foley), infelizmente revelará muito pouco sobre questões diretamente envolvidas em desafios céticos como os que vimos. Ela nada dirá sobre a estrutura das nossas razões para crer e, de modo particularmente mais relevante para o presente debate, ela nada dirá sobre as relações entre o inicialmente plausível princípio de fechamento para a justificação e desafios céticos ou acusações de conhecimento fácil. Isto é um destino particularmente atroz para as pretensões de Greco, já que ele mesmo crê que um resultado do interesse dos epistemólogos pelos desafios céticos deve ser o de esclarecer noções epistemológicas profundas. Mesmo que Greco esteja correto ao afirmar que nem toda crença deve sua justificação à existência de relações evidencias com outras crenças, isto não é em qualquer sentido esclarecedor no que diz respeito aos desafios céticos que se instalam via relações inferenciais. E eu desconfio que Greco (e qualquer outro externalista) precisará fazer pesadas concessões à terminologia (e aos postulados) internalistas para cumprir tal tarefa.

Já mostramos, em outro lugar, ${ }^{26}$ que o confiabilismo genérico é incapaz de dar conta de problemas endereçados aos confiabilistas (particularmente o problema da metaincoerência) sem agregar postulados tipicamente internalistas, postulados de uma espécie que havia sido desqualificada pelo confiabilista. Resumidamente, diante da possibilidade de uma crença $P$, formada no sujeito $S$ por um processo de formação de crenças altamente confiável (e, por isso, para o confiabilista, uma crença justificada) ser desqualificada por uma crença qualquer, R (mesmo que falsa e produzida por um processo muito pouco confiável), ao confiabilista genérico restou o recurso de adicionar à cláusula de confiabilidade uma cláusula antissolapamento, ao modo de Goldman, ${ }^{27}$ que propõe que "a crença $P$ não pode ser desqualificada pelo processo cognitivo de $S$ ", uma cláusula que acusamos ad hoc, já que ela nada explica sobre o porque do mero fato de $S$ subscrever $R$ faz com que $P$ perca sua justificação (lembre-se, $P$ é produzida por um processo confiável e $R$ por um processo não-confiável).

${ }^{26}$ Cf. Alexandre Meyer Luz, Conhecimento e Virtude: Duas Noções de Virtude Intelectual na Epistemologia Contemporânea, 2003 e idem, "Justificação, confiabilismo e virtude intelectual", in: Veritas, p. 191-218.

27 Cf. Alvin Goldman, Epistemology and Cognition, p. 56. 
Uma acusação semelhante será feita aqui. Tomemos o seguinte caso:

O caso do pensador cuidadoso: $S$ tem o caráter virtuosamente formado e, como parte de sua formação, aprendeu que o seguinte princípio intelectual deve ser respeitado: "elimine as hipóteses contrárias". Ele forma o conjunto de crenças $P$, advindas de fonte altamente confiável. $S$ vem a ter contato com enunciados que funcionam como hipóteses contrárias (HC) a $P$, advindas de fontes muito pouco confiáveis. $S$ percebe que não consegue mostrar que as hipóteses contrárias são falsas, mesmo depois de perceber que elas foram produzidas de modo não-confiável. Ele reconhece que não consegue desqualificar as hipóteses e, sendo um pensador cuidadoso, suspende o juízo sobre sua situação epistêmica em relação a $P$.

S está na mesma situação que a vítima do modus tollens de (ACG). A pergunta agora, novamente e considerando que $S$ age virtuosamente, é por quê? Mais uma vez parece que tudo o que o confiabilista pode dizer é, apenas, que "as hipóteses céticas desqualificam o estado cognitivo de $S$ ". Mas isto, além de novamente ser ad hoc, não é explicativo. Como pode o confiabilista explicar que uma crença não justificada pode desqualificar uma crença justificada? E isto fica ainda pior no caso de um confiabilismo fortificado como o de Greco: como pode ele explicar que mesmo uma HC que $S$ percebe incompatível com $P$ e que $S$ percebe não ter sido confiavelmente formada continuar a desqualificar $P$ ? Mais uma vez, parece-me que os pressupostos conceituais confiabilistas não são capazes de dar conta do desafio.

Adicionalmente, parece que Greco não é capaz de oferecer qualquer explicação para o problema do conhecimento fácil. Se $S$ crê justificadamente que $P$, então o que impede que, via princípio do fechamento, $S$ conclua que as hipóteses competidoras de $P$ não estão justificadas? E, pior para Greco, $S$ pode concluir tanto que hipóteses "próximas" quanto hipóteses "distantes" não estão justificadas, um caso flagrante de conhecimento fácil. $S$ pode estar agindo virtuosamente (ele estudou lógica e entende o modus ponens que o leva até a conclusão sobre a justificação das hipóteses competidoras; ele está em uma boa posição para perceber a boa qualidade de sua justificação para $P$ ). Mesmo assim, (ACG) continua a permitir que $S$ caia vítima de um desafio cético.

Queremos utilizar o caso contra Greco (e contra o confiabilismo em geral) como parte de um argumento cumulativo em favor de uma abordagem alternativa da justificação, uma abordagem internalista cancelabilista. A ela nos voltaremos a seguir.

\section{Internalismo e ceticismo}

Se Foley está certo e o ceticismo não pode ser vencido, então alguma diversão para epistemólogos ainda poderá ser garantida com a busca 
de uma explicação para o funcionamento dos argumentos céticos. Como acabamos de ver, o confiabilismo não parece ser capaz de oferecer uma explicação adequada. Creio que os internalistas podem fazer um trabalho melhor, e creio que este trabalho já foi ao menos alinhavado por Peter Klein, num primeiro momento em sua obra fundamental, Certainty, a Refutation of Scepticism ${ }^{28}$ e em alguns trabalhos posteriores. ${ }^{29}$

A despeito do título pretensioso, Certainty é importante em nossa discussão por um motivo bastante particular: Klein oferece ali o mais cuidadoso tratamento do funcionamento das evidências e das contraevidências para a justificação. A estratégia geral consiste

em desenvolver uma análise do conhecimento que contenha condições imunes aos ataques céticos tradicionais. (...) Sustentar que conhecimento, mesmo conhecimento inferencial, é crença verdadeira justificada e absolutamente certa, (...) mostrar que os princípios que subjazem ao ceticismo ou são inaceitáveis ou falham em fornecer um argumento cogente em favor do ceticismo e que há uma caracterização de certeza que é, ou pelo menos que deveria ser, aceitável para o cético e sob a qual muitas de nossas crenças são certas. ${ }^{30}$

Exigir certeza como uma das condições para o conhecimento parece algo temerário, depois do malogro do projeto infalibilista moderno; todavia, qualquer associação entre as pretensões de Klein e as pretensões epistemológicas modernas deve ser evitada, já que o conceito parece ter significados diferentes em cada um dos projetos.

Ele sugere que podemos distinguir entre as seguintes interpretações da noção de certeza:

(i) Certeza psicológica: que remete a um estado psicológico no qual "com a palavra 'certo' nós expressamos convicção completa, a ausência total de dúvida e, com isso, nós procuramos convencer outras pessoas. Esta é a certeza subjetiva". ${ }^{31}$

Estamos a preferir o termo "psicológico" ao wittgensteiniano "subjetivo", aqui, para marcar a distinção entre esta e a próxima interpretação do termo, para nomear aquela situação frequente de

28 Cf. Peter David Klein, Certainty: A Refutation of Scepticism, 1981.

29 Principalmente, Peter David Klein, Closure Matters: Skepticism and Easy Knowledge, in: Philosophical Issues, p. 165-184; idem, There is No Good Reason to be an Academic Skeptic, in: Steven Luper (ed.), Essential Knowledge, p. 299-309; idem, How a Pyrrhonian Skeptic Might Respond to Academic Skepticism, in: Steven Luper (ed.), The Skeptics: Contemporary Essays, p. 75-94; idem, Skepticism, in: Paul Moser (ed.), The Oxford Handbook of Epistemology, p. 336-361.

30 Cf. Peter David Klein, Certainty, p. 4-5.

31 Cf. Ludwig Wittgenstein, On Certainty, p. 194. 
alguém "sentir-se certo" mesmo sem racionalmente dispor de qualquer evidência para tal.

(ii) Certeza evidencial: de modo distinto do "estar certo sem razões", podemos imaginar casos em que, mesmo sem qualquer crença formada sobre a proposição $P$ em questão, o sujeito está na melhor posição para saber, e de modo tal que não teria dúvidas, se considerasse apenas as evidências para $P$, etc. Suponha, por exemplo, que $S$ crê apenas em $P$, em $P \rightarrow Q$ e na validade de modus ponens, parece ser o caso que $S$ está na melhor posição possível para saber que $Q$. S, neste caso, está intitulado à certeza evidencial (mesmo que, por alguma razão, ele não forme a crença de que $Q$ e não tenha, por isso, certeza psicológica de que Q). ${ }^{32}$

(iii) Certeza absoluta e certeza relativa: Na linguagem cotidiana, encontramos, com frequência, expressões que parecem remeter a considerações distintas sobre o grau da certeza. Isto parece ter sua raiz na experiência de manifestação da certeza psicológica, e parece acompanhar a percepção de que a crença varia em graus, e não absolutamente. Em contraposição, todavia, epistemólogos, muito mais interessados na certeza evidencial, têm tratado a noção como sendo absoluta, tal como "plano" ou "aberto".

Isto nos remete a quatro possibilidades. Podemos ter, pelo menos inicialmente, certeza psicológica absoluta, certeza psicológica relativa, certeza evidencial absoluta e certeza evidencial relativa.

Klein propõe como condição para o conhecimento que $S$ esteja intitulado a ter certeza evidencial e certeza psicológica, ambas no sentido absoluto, e defenderá que podemos atingir tal situação, muitas vezes. Sua interpretação peculiar, todavia, encontra-se na ideia de que certeza evidencial absoluta não implica a impossibilidade do surgimento de dúvidas. Em suas palavras:

A questão, pelo menos com respeito à certeza psicológica, não é a de se há ou haverá fundamentos para duvidar de $p$, mas antes se $S$ tem em algum instante qualquer dúvida que seja (razoável ou não) sobre a certeza do enunciado $p$. Conversas sobre o gênio maligno ou outras ocorrências miraculosas podem induzir dúvidas; talvez imaginar eventos desta natureza possa produzir

32 Klein adota as expressões "psicológica" e "evidencial" no lugar dos termo wittgensteinianos "subjetiva" e "objetiva", porque lhe parece que Wittgenstein aceita a implicação, no lugar da mera confirmação, como sendo a relação necessária para a formação de cadeias de crenças. Klein parece, assim, desejar que sua teoria não seja de modo algum confundida com outra que faz exigências bem diferentes das suas. (Cf. Peter David Klein, Certainty, p. 129-130). 
dúvidas, mas isto é irrelevante com respeito a se $S$ estava (ou está) certo de que $p$ num instante antes destes eventos, sejam eles reais ou imaginários. Algo é plano se não é de modo algum curvo; não é requerido, porém, que nada possa induzir encurvamentos. $S$ está absolutamente certo de que $p$ se $S$ não tem dúvida alguma de que $p$. Não é, todavia, requerido que nada possa vir a induzir dúvidas. ${ }^{33}$

O primeiro passo da estratégia geral adotada por Klein fica claro aqui: o de defender a possibilidade de conhecimento ao menos quando as dúvidas geradas pelos desafios céticos não estão presentes, para $S$. O segundo passo da estratégia é, todavia, mais duro: ele consiste em tentar mostrar que mesmo quando os desafios céticos estão presentes nós podemos eventualmente saber. Ele procurará realizar tal tarefa primeiramente valendo-se de uma poderosa explicação de como a crença em falsidades pode funcionar como um cancelador da justificação de $S$ para $P$, ao modo das teorias cancelabilistas (defeasibility theories) da justificação, ${ }^{34}$ e daí mostrando que muitas dos desafios céticos podem não ter força suficiente para cancelar a justificação para $P$. Assim, eventualmente poderemos satisfazer à seguinte definição de conhecimento:

$S$ sabe que $p$ se e somente se:

K1 $p$ é verdadeira

K2 $S$ está certo de que $p$ tendo por base alguma proposição e

K3 e justifica $p$ para $S$

K4 cada cancelador inicial da justificação que $S$ tem para $p$ a partir de $e$ é um cancelador inicial inadequado ${ }^{35}$

A última condição é tipicamente uma cláusula cancelabilista (defeasibility). O caminho evidencial entre e e $p$ pode ser atacado, mas este ataque pode depender de uma falsidade e, assim, ser ineficaz. Isto não significa que cabe a $S$ identificar tal falsidade na origem do ataque cético. Isto significa apenas que a força do ataque pode relativizada à medida que $S$ considera que pode existir tal falsificador.

Temos, portanto, uma defesa das teses de que

(1) não é verdade que não podemos saber que $P$;

e

(2) não é verdade que não podemos ter crença justificada de que sabemos $P$;

33 Id. ibid., p. 133.

34 As ferramentas utilizadas por Klein são avaliadas em Alexandre Luz, A Análise do Conhecimento: o Problema de Gettier e Três Tentativas Internalistas de Solução, 1997.

35 Cf. Peter David Klein, op. cit., p. 150. 
estas teses podem ser satisfeitas porque podemos, eventualmente, não dispor de canceladores adequados da justificação de $P$ (por exemplo, suponha que $S$ não é vítima, em $t$, de qualquer desafio cético).

Todavia, a tese

(1) diante de um desafio cético, $S$ pode afirmar saber que $P$.

não é satisfeita tão facilmente, já que cabe a $S$ o ônus de mostrar que a hipótese cética é, de algum modo, um cancelador inadequado da justificação para $P$.

A estratégia aqui será a de defender a racionalidade de uma posição "pirrônica" de suspensão de juízo diante de teses como (3). O ganho teórico aqui consiste em um refinamento do princípio de fechamento: o condicional transmite justificação prima facie, não justificação ultima facie. Os erros de consideração feitos pelos que imaginam que assumir o princípio leva inevitavelmente à conclusão de que $S$ não sabe que $P$ consiste em supor que se $P$ está justificada em grau $x$, então $R$ também está justificada em grau x e que se não há justificação para $R$, então não há justificação para $P^{36}$

O princípio de fechamento, observado de modo mais detalhado, revelase um princípio de transmissão de evidência, e apenas considerando-se a qualidade da evidência ou da contraevidência que passa pelo princípio ele é um transmissor de justificação. O erro daqueles que consideram que a aceitação do princípio de fechamento leva inevitavelmente à conclusão de que $S$ não sabe que vê zebras na jaula (e, generalizando, à conclusão de que, já que há sempre uma dúvida cética capaz de atacar o consequente do condicional da primeira premissa do princípio, não podemos saber o antecedente, ou seja, não temos conhecimento sobre proposições empíricas em geral) é o erro de supor que as evidências que justificam a crença de que os animais na jaula são zebras é necessariamente cancelada pela possibilidade de eles não serem mulas pintadas. Todavia, deve-se notar que é possível que existam dois caminhos de evidência (evidence paths) independentes, um para a evidência em favor de "os animais são zebras" e outro para a contraevidência, entre "eles não são mulas pintadas" e "os animais são zebras". O caminho de evidências passa, grosso modo, pela visão de animais que parecem zebras, pelo testemunho de outras pessoas, etc. O caminho de contraevidência é

${ }^{36}$ Klein toma o princípio de fechamento para a justificação em sua apresentação padrão (PFJ2). Cremos, todavia, que nossa consideração aqui torna mais elegante as explicações cancelabilistas do ceticismo. Uma defesa do caráter falibilista do princípio do fechamento é sugerida em Cláudio de Almeida, Closure, Defeasibility and Conclusive Reasons, op. cit., p. 301-319. 
independente, parte da possibilidade dos animais serem mulas pintadas, passa pelo condicional do princípio do fechamento e apenas no final de sua caminhada chega, como contraevidência, à proposição de que os animais são zebras. Ou seja, não há contraevidência para a base evidencial que justifica a crença. Portanto, se as evidências são boas, $S$ possui justificação para a crença que não é cancelada e, portanto, está intitulado ao conhecimento mesmo diante das dúvidas céticas. Ao avaliar suas crenças, $S$ é racional ao afirmar que tem boas razões para crer e que também tem canceladores potencialmente bons para sua crença.

Todavia, não se deve tirar demais daqui. O que o exposto acima parece ser capaz de nos oferecer é uma versão sofisticada da tese geral mooreana de que qualquer tese que ataque proposições empíricas deve estar errada. De fato, o exposto não permite que concluamos que as alternativas céticas são falsas; mais sofisticadamente, somente se divide o ônus da prova: se eu creio, depois de ver zebras no zoológico, que há zebras no zoológico e se sou desafiado pelo cético, eu posso confrontálo lembrando que tenho justificação para crer que vi zebras, e que esta justificação me parece tão sólida quanto a justificação da cadeia que sustenta a afirmação de que elas não são mulas pintadas.

O problema do conhecimento fácil também recebe uma boa explicação: a justificação prima facie em favor de "há um computador em minha frente" é transmitida via modus ponens e vira evidência não-conclusiva em favor de "não estou sendo enganado por um gênio maligno zombeteiro". Isto explica porque, dadas as nossas suposições de senso comum, consideramos razoável supor que não estamos sendo enganados por gênios malignos ou o que o valha, mesmo enquanto consideramos isto uma possibilidade. Nenhum conhecimento se dissemina facilmente aqui.

Isso tudo não se constitui, certamente, em uma refutação do ceticismo em geral. Continuamos sem poder sustentar que de fato sabemos que aqueles animais são mulas pintadas, e continuamos vítimas de um tipo poderoso de ceticismo, aquele tipo de ceticismo iterativo que ataca a pretensão de que sabemos que sabemos. Mas, isso, de um modo já anunciado pelos antigos pirrônicos, não é de todo ruim.

\section{Referências}

ALMEIDA, Cláudio de. "Closure, Defeasibility and Conclusive Reasons". In: Acta Analitica, 22 (2007), p. 301-319.

COHEN, S. "Structure and Connection: Comments on Sosa's Epistemology". In: GRECO, J. (ed.). Sosa and his Critics. Oxford: Blackwell, 2004, p. ???.

COHEN, Stewart. "Basic Knowledge and the Problem of Easy Knowledge". In: Philosophy and Phenomenological Research, 65 (2002): 2, p. 309-329. 
DRETSKE, Fred. "Epistemic Operators". In: Journal of Philosophy, 67 (1970), p. 10071023.

FOLEY, Richard. "Three Attempts to Refute Skepticism and Why they Fail'. In: LUPER, Steven (ed.). The Skeptics - Contemporary Essays. Burlington: Ashgate, 2003, p. 64-65.

GETTIER, Edmund. "Is Justified True Belief Knowledge?" In: Analysis, 23 (1963), p. 121-123.

GOLDMAN, Alvin. Epistemology and Cognition. Harvard: Harvard University Press, 1988, p. 56.

GRECO, John. "External World Skepticism". In: Philosophical Compass, 2/4 (2007), seção 1, p. 625-649.

GRECO, John. Putting Skeptics in Their Place - The Nature of Skeptical Arguments and their Role in Philosophical Inquiry. Cambridge: Cambridge University Press, 2000.

KLEIN, Peter David. Certainty: A Refutation of Scepticism. University of Minnesota Press, 1981.

. "Closure Matters: Skepticism and Easy Knowledge". In: Philosophical Issues, 14 (2004), p. 165-184.

. How a Pyrrhonian Skeptic Might Respond to Academic Skepticism. In: LUPER, Steven (ed.). The Skeptics: Contemporary Essays. Burlington: Ashgate Press, 2003, p. 75-94.

. "Skepticism". In: MOSER, Paul (ed.). The Oxford Handbook of Epistemology. Oxford: Oxford University Press, 2002, p. 336-361.

"There is No Good Reason to be an Academic Skeptic". In: LUPER, Steven (ed.). Essential Knowledge. Londres: Longman Publishers, 2004, p. 299-309.

LUZ, Alexandre Meyer. A Análise do Conhecimento: O Problema de Gettier e Três Tentativas Internalistas de Solução. Dissertação de Mestrado. Porto Alegre: PUCRS, 1997.

LUZ, Alexandre Meyer. Conhecimento e Virtude: Duas Noções de Virtude Intelectual na Epistemologia Contemporânea. Tese de Doutorado. Porto Alegre: PUCRS, 2003.

LUZ, Alexandre Meyer. "Justificação, confiabilismo e virtude intelectual". In: Veritas, 50 (2005): 4, p. 191-218.

POPKIN, Richard. The History of Scepticism from Savonarola to Bayle. Oxford: Oxford University Press, 2003.

SOSA, Ernest. "The Raft and the Pyramid: Coherence versus Foundations in the Theory of Knowledge". In: Midwest Studies In Philosophy, 5 (1980):1, p. 3-26.

WILLIAMS, Michael. Problems of Knowledge. Oxford: Oxford University Press, 2000.

WITTGENSTEIN, L. On Certainty. New York: Harper \& Row Publishers, 1969. 